\title{
PENERAPAN METODE MUMTAZAH AL UMM WAL AB DALAM PEMBELAJARAN BAHASA ARAB DI PESANTREN ASSHIDDIQIYAH JAKARTA
}

\author{
Siti Rozinah, Hayaturrohman, Dede Setiawan, Mukhtar Sauri \\ Program Studi Pendidikan Agama Islam, Fakultas Agama Islam, Universitas \\ Nahdlatul Ulama Indonesia (UNUSIA) \\ E-mail: sitirozinah@unusia.ac.id
}

\section{Article Information}

Informasi Artikel

Naskah diterima: 25 Juni 2019

Naskah direvisi: 10 Juli 2019

Naskah disetujui: 30 Juli 2019

Naskah dipublish: 5

Oktober 2019

\section{Kata Kunci Metode}

Mumtazah, Arabic

Learning, Turats Book

\section{Kata Kunci}

Metode Mumtazah,

Pembeajaran

Bahasa Arab,

Kitab Kuning

\section{Abstract}

The aims of this research implementation the the mumtazah method of al umm wal ab Arabic learning Pondok Pesantren Asshiddiqiyah Jakarta. The methode of research is qualitative research. The subject of research is the student student of ulya madrasah diniyah takiyah ma hadul aytam Asshiddiqiyah. The result of this research is the application of the mumtazah method al umm wal ab madrasah diniyah takiyah ma 'hadul aytam asshiddiqiyah Uses 7 strategy, which area sentence, jumlah, Khabar, shilah, shifat, terms and answers. the problem with this method is every student has a different competition in the learning

\begin{abstract}
Abstrak
Penelitian ini bertujuan untuk mengetahui bagaimana penerapan metode Mumtazah Al Umm Wal Ab dalam pembelajaran bahasa Arab dan kitab kuning di pesantren Asshiddiqiyah Jakarta. Penelitian ini merupakan penelitian kualitatif. Subjek penelitian adalah peserta didik kelas ulya Madrasah Diniyah Takmiliyah Ma'hadul Aytam Asshiddiqiyah Jakarta. Penerapan metode Mumtazah Al Umm Wal Ab di Madrasah Diniyah Takmiliyah Ma'hadul Aytam Asshiddiqiyah menggunakan 7 langkah strategi, yaitu kalimat, jumlah, khabar, shilah, shifat, syarat dan jawab. Kendala pelaksanaan metode Mumtazah Al umm wal $a b b$ yaitu santri memiliki karakter dan potensi yang berbeda.
\end{abstract}

\section{PENDAHULUAN}

Tanpa adanya pengetahuan tentang ilmu berbahasa Arab yang baik dan benar tentu orang-orang yang kurang bisa dalam ilmu tata bahasa Arab akan mengandalkan terjemahan yang sudah ada sebagai alat untuk belajarnya, tanpa mengetahui sumber aslinya yang berbahasa Arab. Padahal kalau kita membaca sejarah, terdapat ulama- 
ulama salafi ada yang berbeda pendapat diantara mereka dalam memutuskan suatu hukum karena penerjamahan atau penafsiran satu kata yang berbeda.

Ulama asal Indonesia, Musthafa Bisri dan Quraisy Shihab dalam suatu acara stasiun televisi mengungkapkan bahwa dahulu pernah berbeda pendapat tentang AlQur'an yang diterjemahkan oleh depag RI. Dalam hal itu Quraisy Shihab tidak setuju dengan adanya Al-Qur'an yang diterjemahkan sedangkan Musthafa Bisri menganggap Al-Qur'an yang diterjemahkan itu langkah bijak agar mudah dipelajari oleh umat muslim indonesia yang notabene nya bukan orang Arab. Namun dalam acara itu Musthafa Bisri mengatakan bahwa beliau justru setuju dengan pendapat Quraisy Shihab dahulu, yang mana setelah adanya Al-Qur'an yang diterjemahkan banyak ustadz dadakan yang belajar hanya dari terjemahan tersebut.

Dari pendapat beliau berdua dapat ditarik kesimpulan bahwa Al-Qur'an dan kitab-kitab yang diterjemahkan masih kurang pas dalam usaha untuk mempermudah umat mempelajarinya, bahkan bisa jadi sesat dan menyesatkan apabila tidak dibarengi dengan penguasaan dalam ilmu tata bahasa arab.

Kitab kuning, dalam pendidikan agama islam, merujuk kepada kitab-kitab tradisional berbahasa arab yang berisi pelajaran-pelajaran agama islam (diraasah alislamiyyah) yang diajarkan pada Pondok-pondok Pesantren, mulai dari fiqh, aqidah, akhlaq/tasawuf, tata bahasa arab ('ilmu nahwu dan `ilmu sharf), hadits, taf sir, `ulumul qur'aan, hingga pada ilmu sosial dan kemasyarakatan (mu`amalah). Satu-satunya lembaga pendidikan yang memegang erat metode kitab kuning sebagai alat pendidikan adalah pesantren. Dalam dunia pesantren salafi, pembelajaran bahasa arab berorientasi melalui reading text, seperti shorogan dan bandungan.

Metode Mumtazah Al Umm Wal Ab adalah salah satu dari berbagai macam metode khusus pembelajaran bahasa Arab dan kitab kuning, meode ini sendiri muncul sebagai jawaban dari tuntutan pendiri pesantren Asshiddiqiyah untuk membuat buku praktis dalam mempelajari bahasa Arab dan kitab kuning yang menggabungkan beberapa cabang ilmu yaitu Nahwu, Sharaf, dan bahasa Arab dalam satu buku. 
Penerapan Metode Mumtazah Al Umm Wal Ab Dalam Pembelajaran Bahasa Arab Di Pesantren Asshiddiqiyah Jakarta

\section{METODOLOGI PENELITIAN}

Jenis penelitian yang digunakan dalam penelitian ini adalah penelitian kualitatif. Metode kualitatif adalah penelitian secara ilmiah yang bertujuan untuk memahami suatu fenomena dalam konteks sosial secara alamiah dengan mengedepankan proses interaksi komunikasi yang paling mendalam antara peneliti dan fenomena yang diteliti. Adapun yang menjadi tempat penelitian adalah Madrasah Diniyah Takmiliyah Ma 'hadul Aytam Asshiddiqiyah. Yang ber-alamat di jalan Panjang No.6c kedoya, kecamatan kebon jeruk, kota jakarta barat. Dalam penelitian ini, pengumpulan data dilakukan pada natural setting (kondisi yang alamiah), sumber data primer. dan teknik pengumpulan data menggunakan tiga teknik yaitu observasi (berperanserta aktif dalam pengamatan lapangan), in depth interview (wawancara mendalam), dan dokumentasi.

\section{KAJIAN TEORI}

Secara lughawi metode dalam Bahasa arab disebut dengan istilah thariqah yang berarti jalan. Terdapat beberapa pendapat dari definisi metode: a) Menurut Radliyah Zaenuddin metode adalah rencana yang menyeluruh yang berkenaan dengan penyajian meteri seacara teratur dimana tidak ada bagian yang lain kesemuanya beradasarkan atas approach (penedekatan) yang telah ditentukan sebelumnya ${ }^{1}$. b) Menurut wina sanjaya metode adalah cara yang digunakan untuk mengimplementasikan rencana yang sudah disusun dalam kegiatan ny ata agar tujuan yang telah disusun tercapai secara optimal $\left.{ }^{2} . c\right)$ Menurut muhibbin syah metode diartikan sebagai cara yang berisi prosedur buku untuk melaksanakan kegiatan penyajian meteri pelajaran kepada peserta didik $^{3}$.

Dari beberapa definisi tersebut dapat disebutkan bahwa metode merupakan suatu alat atau cara untuk mencapai tujuan proses pembelajaran. Metode juga berhubungan dengan cara yang memungkinkan peserta didik memperoleh kemudahan dalam rangka mempelajari bahan ajar yang disampaikan oleh guru.

Kata Mumtazah berasal dari Bahasa arab yang bermaka istimewa atau sempurna. sebuah metode yang istimewa untuk pembelajaran Bahasa arab, kitab kuning dan Al-Qur'an. Sedangkan Al umm wal Ab sendiri bermakna Ayah dan ibu yang juga

\footnotetext{
${ }^{1}$ Radliyah Zaenuddin, Metodologi dan Strategi Alternatif pembelajaran bahaa arab, (Cirebon:Pustaka Rihlah Group, 2005), h.31

${ }^{2}$ Wina sa njaya, strategi pembelajaran berorientasi standar proses pendidikan, (Jakarta:kencana prenada media group,2008), h.147

${ }^{3}$ Muhibbin syah, psikologi pendidikan, (bandung:remaja rosdakarya, 1995)
} 
berasal dari Bahasa Arab,sebuah buku yang berisi metode Mumtazah didalamnya. Maksud dari makna ayah dan ibu adalah nahwu dan sharaf, duacabang ilmu yang wajib dipelajari ketika ingin menguasai bahasa Arab dan kitab kuning yang sudah digabungkan atau disatukan didalam buku ini ${ }^{4}$. Metode Mumtazah dari buku Al umm $w a l A b$ ini digadang-gadang oleh penemu sebagai sebuah metode tabarukan yang tepat guna dan tepat sasaran dalam membantu guru dan siswa untuk mempelajari Bahasa Arab, kitab kuning dan Al-Qur'an yang telah dipraktekan kepada sejumlah siswa dengan hasil yang cukup memuaskan.

Sejarah dari lahiranya metode Mumtazah ini berawal dari sebuah penataran yang diikuti oleh penemu, yaitu Ustadz Syukri Ghozali (Penagajar sekaligus salah satu pimpinan di Pesantren Asshiddiqiyah Jakarta) pada tahun 1987 tentang metode baru pembelajaran Al-Qur'an. Didalam penataran itu beliau termotivasi dari kalimat yang diucapkan oleh narasumber acara tersebut yaitu " mengapa kita harus mencari dan menggunakan metode baru sedangkan metode lama sudah berjalan dan dipakai oleh banyak guru dan pelajar?" yang jawabannya adalah karena metode lama yang sudah dipakai membutuhkan waktu yang lama sehingga kurang ef ektif jika terus dipakai tanpa adanya sebuah evaluasi dan perbaikan. Dari situlah terfikirkan oleh beliau untuk menemukan sebuah metode baru yang bisa dengan cepat memahami Bahasa arab, kitab kuning dan Al-Qur'an ${ }^{5}$.

Setelah ada motivasi itu, langkah awal beliau adalah mempraktekan metodemetode yang beliau punya pada siswa didalam pelajaran yang sebenarnyanya bukan pelajaran bahasa arab namun beliau tambahkan sedikit demi sedikit pelajaran Bahasa Arab tentang nahwu dan shorof, langkah demi langkah tahap demi tahap setelah sekian waktu dirasakan bahwa metode tersebut berbuah hasil, akan tetapi pada waktu itu belum terfikirkan untuk membukukan dan menyebarluaskan metode tersebut. Sampai pada akhirnya suatu hari didalam sebuah pertemuan para pimpinan pesantren Asshiddiqiyah, pengasuh pesantren, yaitu Noer Muhammad Iskandar meminta supaya ada yang mencarikan atau membuat metode baru yang lebih baik lagi untuk membantu

\footnotetext{
${ }^{4}$ M. Syukri Ghazali, Penemu Metode Mumtazah Al Umm Wal Ab, Rumah Kediaman Jakarta, Wa wancara Pribadi.

${ }^{5}$ M. Syukri Ghazali, Penemu Metode Mumtazah AlUmm Wal Ab, Rumah Kediaman Jakarta, Wa wancara Pribadi,
} 
pembelajaran Bahasa Arab, kitab kuning dan Al-Qur'an, langsung saja beliau katakan bahwa beliau memiliki metode baru yang bagus dan sudah dipraktekan pada siswa. Namun belum diberi respon yang lebih oleh pengasuh sampai beberapa kali dan akhirnya pengasuh merespon dan meminta contoh siswa yang telah diajarkan metodenya. Tanpa menjelaskan apa saja yang akan diujikan oleh pengasuh, langsung saja semua siswa yang telah diajarkan oleh beliau berjumlah 32 dibawa menghadap dan dites langsung didepan beliau melalui soal lisan. Tanpa disangka oleh pengasuh sejumlah siswa yang dites berhasil dengan baik menjawab soal-soal yang diajukan oleh pengasuh 6 .

Pada akhirnya dimintalah Ustadz Syukri Ghazali supaya membukukan dan menyebarluaskan metode yang dipakai kepada pesantren Asshiddiyyah Pusat dan Cabangnya. Dinamakanlah metode tersebut dengan Metode Mumtazah dengan pemandunya buku Al Umm Wal Ab yang berjumlah 3 jilid.

\section{MADRASAH DINIYAH TAKMILIYAH MA'HADUL AYTAM ASSHIIDIQIYAH JAKARTA}

Madrasah Diniyah Takmiliyah adalah suatu satuan pendidikan keagamaan Islam non formal yang menyelenggarakan pendidikan Islam sebagai pelengkap bagi siswa pendidikan umum. Kegiatan madrasah diniyah merupakan pendidikan tambahan sebagai penyempurna bagi siswa di sekolah Dasar (SD), sekolah menengah pertama (SMP), dan sekolah menengah atas (SMA) yang hanya mendapat pendidikan Agama Islam dua jam pelajaran dalam satu minggu.

Madrasah Diniyah Takmiliyah atau disingkat menjadi MDT adalah suatu lembaga pendikan Islam yang dikenal sejak lama bersamaan dengan masa penyiaran Islam nusantara. Pengajaran dan pendidikan Islam timbul secara alamiyah melalui proses akulturasi yang berjalan halus, perlahan sesuai dengan kebutuhan masyarakat sekitar.

Madrasah Diniyah Takmiliyah Ma'hadul Aytam Asshiddiqiyah Jakarta merupakan suatu lembaga pendidikan yang berada di bawah naungan Pondok Pes antren Asshiddiqiyah pusat yang beralamatkan di jalan panjang No. 06 C, Kedoya Utara, Kebon Jeruk Jakarta Barat. Pendirinya adalah Dr. K.H. Noer Muhammad Iskandar SQ,

\footnotetext{
${ }^{6}$ M. Syukri Ghazali, Penemu Metode Mumtazah Al Umm Wal Ab, Rumah Kediaman Jakarta, Wa wancara Pribadi
} 
didirikan pada bulan Februari tahun 2009 dengan tujuan memberikan pendidikan bagi yang kurang mampu, baik pendidikan umum ataupun pendidikan agama.

Madrasah Diniyah Takmiliyah Ma'hadul Aytam Asshiddiqiyah Jakarta didirikan dengan program beasiswa khusus bagi anak yatim, piatu dan kaum dhu'afa. Penamaan ma'had aytam yang artinya pondok anak-anak yatimtidak mengkhususkan anak-yatim saja akan tetapi juga bagi anak-anak yang kurang mampu dan anak-anak putus sekolah.

1. Visi dan Misi Madrasah Diniyah Takmiliyah Ma'hadul Aytam Asshiddiqiyah Jakarta

Setiap suatu lembaga pendidikan pasti memiliki sebuah visi dan misi yang telah ditetapkan, sebagaimana juga MDT. Ma'hadul Aytam Asshiddiqiyah Jakarta yang memiliki visi yaitu :“ Membentuk dan mengkader generasi yang Rabbani, yang mandiri, bersahaja dan berwawasan keagamaan yang komprehensif, terampil dan kreatif”.Adapun misi MDT Ma'hadul Aytam Asshiddiqiyah Jakarta yang merupakan sebuah pendukung dalam pencapaian visinya, yaitu : "mencetak dan mendidik kelompok anak- anak mariginal menjadi putra-putri bangsa yang berpendidikan mumpuni dan berakhlakul Karimah".

Penerapan misi MDT. Ma'hadul Aytam Asshiddiqiyah Jakarta terhadap siswa di sekolah di awali dengan pengajaran akhlakul karimah dan kedisiplinan. Yang mana dengan baiknya akhlak siswa maka akan baik juga segala hal tentang dirinya. Akhlak baik terhadap guru maupun akhlak kepada sesama teman yang dari berbagai daerah. Seperti membiasakan mengucapkan salam kalau bertemu, mencium tangan, berkata sopan dan lain-lain. Begitu juga dengan cara meningkatkan kedisiplinan siswa, dengan cara pengajaran disiplin datang tepat waktu, disiplin dalam belajar, disiplin dalam berjamaah, dan disiplin dalam segala hal, maka kebiasaan disiplin tersebut akan mendarah daging dalam diri siswa meskipun siswa tersebut sudah lulus, terutama disiplin dalam hal ibadah. Jadi jikalau ada salah satu santri yang akhlaknya kurang sopan, sering bertengkar sesama teman, ataupun kurang disiplin nanti akan di tegur dan akan mendapatkan sangsi.

Penerapan visi MDT Ma'hadul Aytam Asshiddiqiyah dengan cara mengajarkan anak-anak berbagai ilmu keagamaan dari pembelajaran ala pesantren salaf, selain itu juga untuk membentuk jiwa kreatif mereka di ajarkan pembelajaran tentang 
eterpreunership dalam berwira usaha. Serta diajarkan beberapa keterampilan yang nantinya ketika mereka lulus, mereka sudah mendapatk an bekal secara keilmuan dan keahlian yang dapat digunakan dimasyarakat dimana mereka berasal.

2. Kurikulum Madrasah Diniyah Takmiliyah Ma'hadul Aytam Asshiddiqiyah Jakarta

Kurikulum dapat diartikan sebagai tujuan pengajaran, pengalaman-pengalaman belajar, alat-alat pelajaran dan cara-cara penilaian yang direncanakan dan cara-cara penilaian yang direncanakan dan digunakan dalam satu lembaga pendidikan. Kurikulum juga dipandang sebagai suatu program pendidikan yang direncanakan dan dlaksanakan untuk mencapai tujuan-tujuan pendidikan tertentu. Kurikulum yang digunakan di MDT. Ma'hadul Aytam Asshiddiqiyah Jakarta adalah kurikulum tingkat satuan pendidikan (KTSP) yang didasarkan pada ketentuan-ketentuan yang di tetapkan dengan PP No. 19 tahun 2007 tentang pendidikan dan keagamaan.

\section{PELAKSANAAN METODE MUMTAZAH AL UM WAL AB}

Metode Mumtazah Al Um Wal Ab adalah salah satu metode yang baik dan cocok digunakan untuk pembelajaran bahasa arab dan kitab kuning. Selain mudah dipahami dan diserap oleh santri atau peserta didik, penggunaan metode ini dibekali 1000 soal latihan perjilid yang harus dijawab dengan benar secara keseluruhan. Secara benar keseluruhan yang dimaksud adalah tidak akan disalahkan soal latihan yang sudah dijawab apabila tidak benar akan tetapi diulang samp ai benar dengan diberikan kisi-kisi untuk menyelesaikan.

Dalam usaha mendapatkan hasil yang baik dalam penerapan suatu metode pembelajaran, Guru merupakan salah satu komponen utama yang tidak dapat dipisahkan keberadaannya dalam prosesnya. Selain guru, buku atau kitab yang berisikan metode yang akan diterapkan juga merupakan komponen yang sangat penting, agar supaya unsur-unsur dan syarat-syarat dalam penerapan metode tersebut dapat dilaksanakan sebagaimana semestinya.

Penerapan metode mumtazah menggunakan bukuAl um Wal ab yang berjumlah 3 jilid, yang masing-masing jilid memiliki tingkatan atau kompetensi berbeda yang harus dicapai.

1. Kompetensi yang harus dicapai metode mumtazah al um wal abb 
a) Kompetensi metode mumtazah dalam 3 jilid buku al um wal ab. Mampu: menghafal materi yang sudah ditentukan, muhadatsah, menulis, membaca dan menterjemahkan baik dari indonesia ke arab ataupun sebaliknya.

b) Jilid 1, peserta didik mampu:Mengenal dan memahami kalimat dan susunannya ( isim, fi'il dan huruf). Hafal kosakata yang disajikan di dalam buku al um wal abb jilid 1 Menulis dengan benar kosakata yang sudah dihafalkan.

c) Jilid 2, peserta didik mampu: Hafal kosakata yang disajikan di dalam buku al um wal abb jilid 2, Menulis dengan benar kosakata yang sudah dihafalkan, Membaca tulisan arab tanpa harakat secara baik dan benar, Menterjemahkan dari bahasa indonesia ke arab menggunakan susunan jumlah fi'liyah.

d) Jilid 3, peserta didik mampu: Hafal kosakata yang disajikan di dalam buku al um wal abb jilid 3, Menulis dengan benar kosakata yang sudah dihafalkan. Meng i'rab kalimat yang sudah disediakan di dalam jilid 3 secara benar. Mengartikan ayat-ayat al quran sesuai i'rab. Menterjemahkan ayat-ayat AlQur'an.

e) Latihan per jilid. Di dalam satu jilid buku Metode Mumtazah Al Umm wal ab terdapat 1000 butir latihan yang harus dikerjakan peserta didik dengan predikat sempurna, atau tidak boleh ada satu butirpun dari soal yang tidak terjawab dengan benar.

2. Komposisi waktu pembelajaran; Komposisi waktu adalah 80-85 menit dengan pembagian:

a) 5-20 menit untuk membaca do'a, absensi, membaca pokok-pokok pelajaran atau klasikal

b) 40-50 menit untuk kegiatan pembelaran inti.

c) 10-15 menit untuk memberi nasihat dan do'a penutup.

3. Proses pembelajaran metode Mumtazah Al Um Wal Ab

Seperti yang disebutkan di awal, bahwa dalam pembelajaran metode Mumtazah Al Um Wal Ab kompetensinya adalah menghafal, muhadatsah, menulis, membaca dan menterjemahkan. Maka dalam pembelajaran ini tidak pada tahap awal atau jilid awal akan tetapi pada jilid 2. Dalam menggunakan metode ini ada langkah-langkah yang harus dilakukan diantaranya adalah menggunakan strategi 7 langkah dan kunci 5977.

a) Strategi 7 langkah adalah urutan dari pembelajaran materi yang ada dalam buku: 
Penerapan Metode Mumtazah Al Umm Wal Ab Dalam Pembelajaran Bahasa Arab Di Pesantren Asshiddiqiyah Jakarta

Pertama adalah mempelajari kalimat, yaitu memahami jenis-jenis kalimat yang berjumlah 3: isim, fi'il dan huruf. Kedua adalah memelajari tentang jumlah, meliputi: Jumlah ismiyah, jumlah fi'liyah, jumlah dzarfiyyah, jumlah dzatul wajhain dan jumlah syarthiyyah. Ketiga mempelajari jenis-jenis khabar, meliputi: khabar jumlah fi'liyah, khabarjumlah ismiyah, khabar dzarah, khbarjar majrur dan khabar mufrad. Keempat adalah pembelajaran shilah, meliputi shilah jumlah fi'liyah, Shilah jumlah ismiyah, Shilah dzaraf, Shilah jar majrur dan Shilah dzatul wajhain. Kelima mempelajari shifat atau Na'at yaitu: Na'at Isim masdar, Na'at isim fa 'il, Na 'at isim maf'ul, Na'at sifat musyabihat, Na 'at af'alut tafdhil, Na 'at sifat mubalaghah, Na'at lafat ذات atau ذات , $\mathrm{Na}$ 'at fill madhi lugawi mazid tasydid, Na'at isim mausul, Na'at fiil mudhori lughawi mazid tasydid, Na'at isim nisbat, Na'at ismyah, $N a$ 'at dzaraf dan Na'at jar majrur. Keenam syarat dan yang ketujuh adalah jawab dalam pembelajaran langkah yang dipelajari adalah tengtang Huruf Syarat dan Jawab syarat dengan menggunakan huruf ف

b) Kunci 5977 adalah pokok praktek metodenya Yang dimaksud kunci 5977 adalah 5M, 9H, 7I dan 7E $5 \mathrm{M}$ yaitu: menghafal, muhadatsah, menulis, membaca dan menterjemahkan.

$9 \mathrm{H}$ yaitu: hafal tashrif fi 'il madhi lughawi, hafal tashriffi'il mudhari lughawi, hafal tashrif fi'il amar lughawi, hafal tashrif fi'il nahi lughawi, hafal tashrif isim fa'il lughawi, hafal tashrif isim maf'ul lughawi, hafal semua hurufjar, hafal dzarafmakan dan zaman, hafal isim-isim sama'i.

7 I yaitu: identifikasi kalimat, identifikasi jumlah, identifikasi khabar, identifikasi shilah, identifikasi shifat, identifikasi syarat dan jawab dan terakhir identifikasi jawab dengan huruf "Fa"

7 E yaitu: evaluasi jumlah mufidah darifi'il madhi, evaluasi jumlah mufidah darifi'il mudhari, evaluasi jumlah mufidah dari fi'il amar, evaluasi jumlah mufidah dari fi'il nahi, evaluasi jumlah mufidah dari isim fa 'il atau isim maf'ul, evaluasi jumlah mufidah dari isim sama ' $i$ atau isim mustaq, evaluasi jumlah mufidah dari dharafmakan atau jar majrur, evaluasi tersebut harus dilakukan secara berkesinambungan .

Adapun langkah-langkah guru dalam pembelajaran bahasa arab dan kitab kuning menggunakan metode Mumtazah Al Um Wal Ab adalah sebagai berikut: 
1) Sebelum masuk kelas, guru mempersiapkan keperluan dalam kegiatan pembelajaran seperti: spidol, buku absen dan buku al Umm Wal Abb.

2) Guru memasuki kelas atau tempat belajar dengan mengucapkan salam, menyapa santri lalu duduk mengawali tawasul fatihah, lalu meminta salah satu santri untuk memimpin do'a akan belajar, di lanjutkan membaca tasyahud sholat sampai selesai.

3) Guru mengabsen santri, dilanjutkan satu persatu setoran kosakata yang sudah ditetentukan untuk dihafal pada pertemuan sebelumnya sammpai selesai.

4) Guru mengingatkan kembali materi sebelumnya supaya lebih memudahkan materi selanjutnya yang masih berkesinambungan.

5) Guru menyampaikan materi jumlah dzarfiyah, menyebutkan contohnya dengan di artikan perkata diikuti seluruh santri sampai selesai.

6) Santri satu persatu diminta membaca contoh dzaraf yang berbahasa Arab berharakat lengkap satu santri satu kalimat, setelah membaca contoh arab berharakat lengkap senjutnya membaca contoh berbahasa arab yang tidak berharakat lengkap, lalu membaca contoh berbahasa arab tanpa harakat sampai benar keseluruhan.

7) Guru mengambil nilai dari latihan membaca contoh materi, materi tidak akan dilanjutkan atau ditambah sebelum latihan membaca benar semua.

8) Guru memberikan nasihat pentingnyabisa berbahasa arab lalu meny ampaikan materi untuk pertemuan selanjutnya dan memberikan kosakata yang harus dihafal.

9) Guru meminta salah satu santri memimpin do'a setelah belajar, lalu ditutup salam dan santri satu persatu bergantian bersalaman dengan guru untuk keluar kelas.

Guru sebagai tenaga pendidik tidak lepas dari kendala yang dihadapinya, terutama dalam perannya sebagai suri tauladan bagi peserta didik dalam hal kedisiplinan, salah satunya adalah kedisiplinan dalam kehadiran. Jumlah kehadiran yang kurang dari komposisi yang ditentukan akan mempengaruhi kompetensi dalam pembelajaran. Solusi untuk kendala dalam pelaksanaan pembelajaran metode Mumtazah

1) Santri harus diberikan terget dan peraturan yang sama dalammengerjakan tugas yang diberikan oleh guru.

2) Terhadap santri yang tidak suka pelajaran bahasa arab dan Al-Qur'an, guru harus berperan aktif dalam proses belajar mengajar dan memberikan masukan betapa pentingnya bahasa arab dan Al-Qura'n, terutama bagi umat muslim. 
3) Guru memberikan arahan kepada santri yang daya serap bagus supaya berasamasama dalam belajar membantu santri yang memiliki daya serap rendah.

\section{KESIMPULAN}

Berdasarkan hasil penelitian yang diperoleh, dapat disimpulkan bahwa penerapan metode Mumtazah Al Um Wal Ab di madratsah takmiliyah ma'hadul aytam asshiddiqiyah Jakarta dalam penerapan metode Mumtazah Al Um Wal Ab unsur-unsur itu adalah: a) Program yang dilaksanakan: Menghafal, muhadatsah, menulis, membaca dan menterjemahkan. b) Pelaksanaan: dalam melaksanakan metode Mumtazah Al Um Wal Ab menggunakan langkah-langkah sebagai berikut: Guru menyampaikan materi, menyebutkan contohnya dengan di artikan perkata diikuti seluruh santri sampai selesai.Santri satu persatu diminta membaca contoh darimateri yang berbahasa Arab berharakat lengkap satu santri satu kalimat, setelah membaca contoh arab berharakat lengkap senjutnya membaca contoh berbahasa arab yang tidak berharakat lengkap, lalu membaca contoh berbahasa arab tanpa harakat sampai benar keseluruhan .

\section{DAFTAR PUSTAKA (BIBLIOGRAPHY)}

Abdurrahman Ginting. Esensi Praktis Belajar dan Pembelajaran, Bandung: Humaniora, 2008.

Abu Ahmadi dan Joko Tri Prastya, Strategi Belajar Mengajar, Bandung: CV Pustaka Setia, 2005.

Agus Suryana. Panduan Praktis Mengelola Pelatihan, Jakarta : Edsa Mahkota, 2006.

Azhar Arsyad. Media Pembelajaran, Cet. XV; Jakarta: PT Raja Grafindo Persada, 2011.

Azyumardi, Azra. Pendidikan Islam: Tradisidan Modernisasi Menuju Millenium Baru, Jakarta: Logos, cet. I, 1999.

Hamzah AL. Keutamaan dan Kewajiban Mempelajari Bahasa Arab, Penebar Swadaya:2012.

Haris Herdiansyah. Metodologi Penelitian Kualitatif Untuk Ilmu-Ilmu Sosial, Salemba Humanika, Jakarta: 2011.

Harjanto, perencanaan pengajaran, Jakarta: rineka cipta, 2005.

M. Syukri Ghazali. Penemu Metode Mumtazah Al Umm Wal Ab, Rumah Kediaman Jakarta, Wawancara Pribadi, Jakarta, 29 September, Pukul 07.30 WIB - 08.15. 
Penerapan Metode Mumtazah Al Umm Wal Ab Dalam Pembelajaran Bahasa Arab Di Pesantren Asshiddiqiyah Jakarta

Radliyah Zaenuddin. Metodologi dan Strategi Alternatif pembelajaran bahaa arab, Cirebon:Pustaka Rihlah Group, 2005.

Sugiyono, Metode Penelitian Kuantitatif Kualitatif dan R\&D, Bandung: Alfabeta, 2009.

Tukiran Taniredja. Model-model Pembelajaran Inovatif, Cet. II; Bandung: Alfabeta, CV, 2011.

Wina Sanjaya. Strategi Pembelajaran Berorientasi Standar Proses Pendidikan, Jakarta: Kencana Prenada Media Group, 2008.

Yayan Nurbayan. Metodologi Pembealajaran Bahasa Arab, Bandung : Zein El Bayan, 2008.. 